\title{
Primeiro relato da ferrugem (Olivea tectonae) em plantas de teca no estado da Bahia
}

\author{
Jaqueline Maria Oliveira Nascimento da Silva ${ }^{1} \oplus$, Carlos Augusto Dórea Bragança ${ }^{1} \oplus$, Thaís Emanuelle Feijó de \\ Lima $^{1} \oplus$, Juan Manuel Anda Rocabado ${ }^{1}$, Fabiano Machado Martins ${ }^{1} \mathbb{\oplus}$, José Luiz Bezerra ${ }^{1} \oplus$
}

${ }^{1}$ Universidade Federal do Recôncavo da Bahia, Laboratório de Microscopia, Centro de Ciências Agrárias, Ambientais e Biológicas, Rua Rui Barbosa, 710, CEP: 44380-000, Cruz das Almas-BA, Brasil.

Autor para correspondência: (jaquelinenascimentoufrb@gmail.com)

Data de chegada: 18/04/2017. Aceito para publicação em: 07/11/2017.

$10.1590 / 0100-5405 / 178718$

A teca é uma espécie florestal que apresenta grande potencial para a exploração devido a sua madeira que possui rusticidade, grande rendimento, rápido crescimento, tolerância ao calor, pragas e doenças, sendo empregada na fabricação de móveis e na construção naval (1, 9). Dentre as doenças que ocorrem nessa espécie vegetal, a ferrugem causada pelo fungo Olivea tectonae, tem sido, amplamente estudada, visto que, causa desfolha intensa e prematura em todas as fases fenológicas da planta, reduzindo a taxa fotossintética, o crescimento e consequente queda na produção $(2,10,15)$. No continente americano foi relata no Panamá, seguido por Costa Rica, Atlântico e zonas do Pacífico, no Equador, no México, na Colômbia, na Austrália e em Cuba $(4,5,6,7,8,11,14)$. No Brasil, foi relatada em Sinop - Mato Grosso em 2009, posteriormente nos estados de Minas Gerais, Maranhão, Tocantins, São Paulo, Amazonas, Goiás e Sergipe (1, 3, 10, 12, 13, 15). Em junho de 2016 esta doença foi observada em plantas de teca cultivadas na Universidade Federal do Recôncavo da Bahia, Campus de Cruz das Almas - Bahia. Foram observados na superfície adaxial da folha de teca os primeiros sintomas da doença, caracterizados por pequenas manchas marrons, cloróticas que se tornam necróticas e coalescem podendo atingir toda a superfície foliar e causar a desfolha
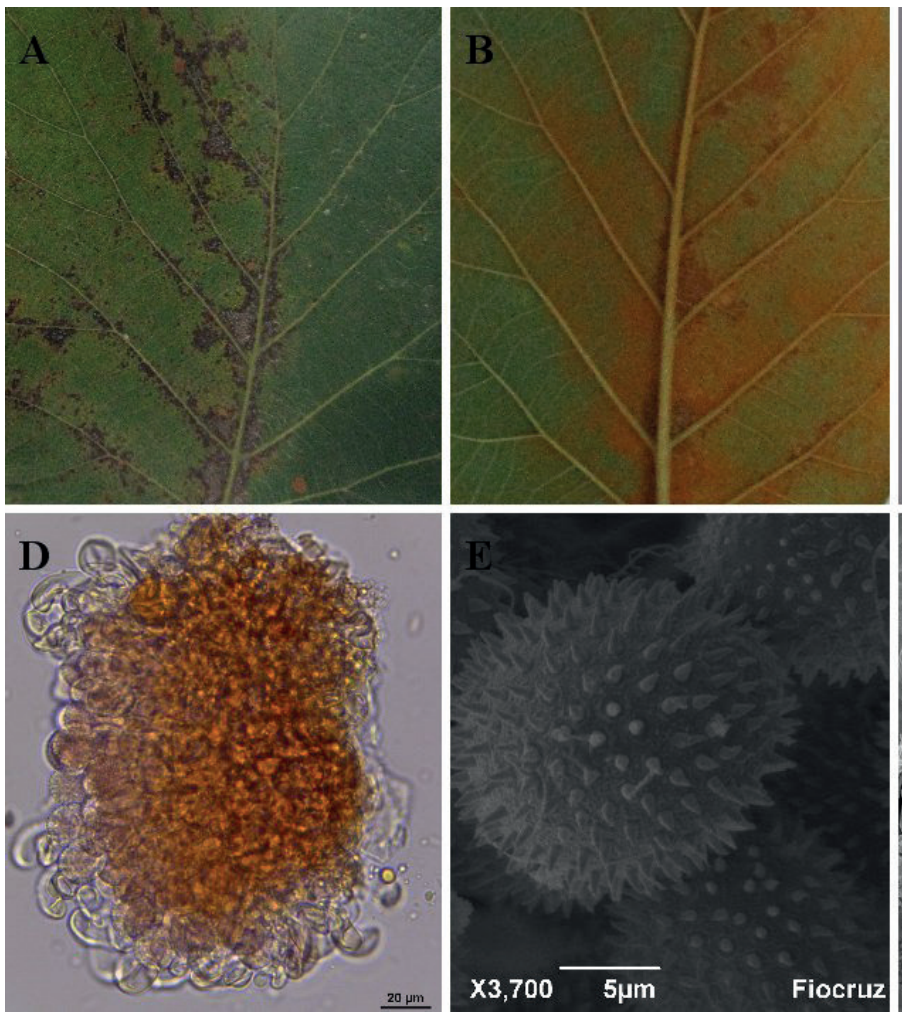

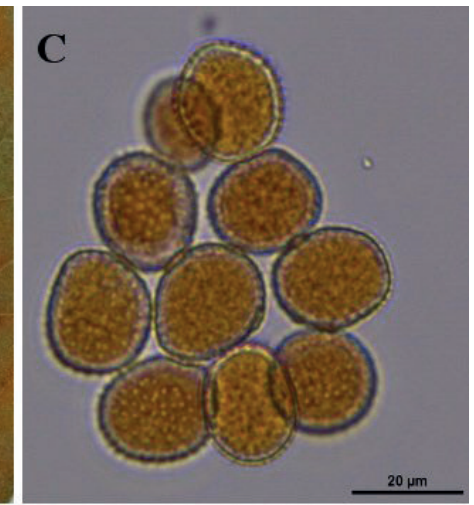

(Figura $1 \mathrm{~A}$ ). Na parte abaxial das folhas foram vistas inúmeras pústulas amareladas dispersas em toda a folha caracterizando os sinais da doença (Figura B). Na observação em lupa foram visualizados os uredínios hipófilos, dispersos, subepidermais, irrompentes, de coloração laranja amarelado brilhante, pequenos, com 0,2 - 0,5mm de diâmetro. Urediniósporos subglobosos, obovoides a elipsoides, de coloração laranja amarelado, com $18-26 \times 14-20 \mu m$ foram visualizados em microscopia de luz e MEV (Figura 1 C - E) apresentando ornamentação equinulada, hialina, com $2 \mu \boldsymbol{m}$ de espessura. Poros germinativas não vistos; Paráfises periféricas, encurvadas, unidas na base, formando um plexo de hifas entrelaçadas, cilíndricas, inchadas no ápice, com $30-45 \times 10-14 \mu \mathrm{m}$, parede lisa, de coloração hialina a castanho claro, com 2,5 $\boldsymbol{\mu m}$ de espessura (Figura 1 D - F). Com base em caracteres morfológicos, foi possível identificar o patógeno como Olivea tectonae. Esse patógeno pertence a ordem Pucciniales, família Chaconiaceae, tem como sinônimos: Chaconia tectonae (T.S. Ramakr. \& K. Ramakr.), Olivea neotectonae Buriticá \& Salazar-Yepes, Tegillum tectonae (Racib.) Doweld. Trata-se de uma ferrugem autoécia cujo ciclo de vida completo é desconhecido. Este é o primeiro relato de Olivea tectonae no estado da Bahia.

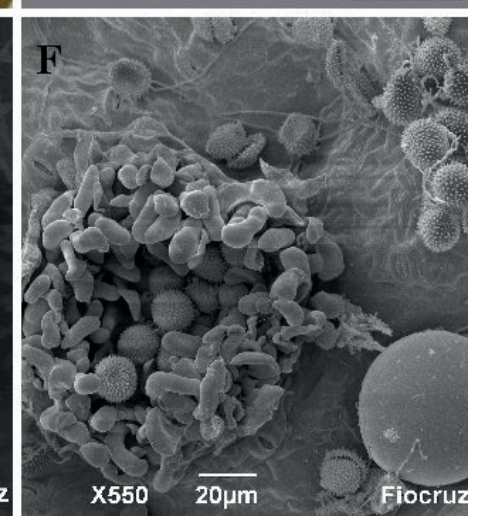

Figura 1 Sintomas de ferrugem em plantas de teca (Tectona grandis.) causados por Olivea tectonae. Folha de teca apresentando limbo com aspecto de queima (A); Pústulas com intensa esporulação na face abaxial do limbo foliar (B); Uredinósporos $(20 \mu)(C)$ e Paráfises $(20 \mu)$ sobre microscopia de luz (D); Urediniósporos (E) e Paráfises $(\mathrm{F})$ sob microscopia eletrônica de varredura. 


\section{REFERÊNCIAS}

1. Bonaldo, S. M., Barceli, A. C., Trento, R. A., Gasparotto, F. e Taffarel, C. Summa Phytopathologica, Botucatu, v. 37, n. 3, p. 153, 2011.

2. Buriticá, P. \& Salazar, M. Revista Facultad Nacional de Agronomia de Medellín, v.60, p.3645- 3655, 2007.

3. Cabral, P.G.C.; et al. Australasian Plant Disease Notes, 5, p.113 - 114, 2010.

4. Cespedes, P. B; Yepes, M. S. Revista Facultad Agronomia, Medellin, v. 60, n.1, p.3645-3655, 2007.

5. Cibrián T. D.; García Díaz, S. E.; Alvarado Rosales, D. Universidad Autónoma Chapingo, México, p.307-311, 2007.

6. Daly, A.M.; Shivas, R.G.; Pegg, G.S.; Mackie, A.E. Australia. Australasian Plant Disease Notes, Australia v.1, p.25-26, 2006.

7. EPPO, 2005. n.8. http://archives.eppo.int/EPPOReporting/2005/Rse-0508 pdf.
8. Esquivel, E. Agrociencia Panamensis, v. 3, n. 4.2 p., 2003.

9. Figueiredo, E. O.; Oliveira, A. D. de; Scolforo, J. R. S. Cerne, Lavras, v. 11, n. 4, p.342-353, 2005

10. Gasparotto, L \& Pereira, J, C, R. EMBRAPA Amazônia Ocidental, 3p (Documento Tecnico, 101) 2013.

11. Macias, J. y Arguedas, M. Manejo Integrado de Plagas y Agroecología (Costa Rica). n. 71; p. 119 - 120, 2004.

12. Marques, M. L. S.; Jesus, J. M. I.; Virtuoso, M. C. S.; Marques, V. S.; Santos G. R. Revista verde de agroecologia e desenvolvimento sustentável, Pomba - PB - Brasil, v.10, n.5, p.21-25, 2015.

13. Mesquita, J. B.; Santos I. T. B. F.; Ribeiro, G. T.; Santos, M. J. C. Summa Phytopathologica., Botucatu, v. 42, n. 3, p. 278-279, 2016.

14. Pérez, M.; López, M.O.; Martí, O. Plant Pathology, UK, v. 58, n. 2, p. 397, 2009.

15. Pieri, C.; Passador, M. M.; Furtado, E. L.; Carvalho Junior, A. A. Summa Phytopathologica, Botucatu, v. 37, n. 4, p. 199-201, 2011. 